\title{
MECHANICAL PROPERTIES AND WELDING POWER OF FRICTION STIRRED AA2024-T35 JOINTS
}

\author{
H. Abd El-Hafez \\ Suez Canal University, Faculty of Engineering, 42523 Port Said, Egypt
}

\begin{abstract}
This study is concerned with the effect of friction stir welding parameters on the mechanical properties and the consumed welding power for AA2024-T35 joints. AA2024-T35 was friction stir welded at different welding speeds (16, 40 and $80 \mathrm{~mm} / \mathrm{min}$ ), rotation speed $(900,1120$ and 1400 $\mathrm{rpm}$ ) and two tool profiles (triangular and square). The welding power was measured and evaluated with two previously established models [1,2]. The tool profile as well as the welding speed showed significant effect on the microstructure especially at lower welding speeds. The increase of the welding speed improves the mechanical properties for both tool profiles whereas it has an insignificant effect on the welding power. The square profile produced better mechanical properties and consumed more power, at $40 \mathrm{~mm} / \mathrm{min}$, than the triangular one. Also, the welding speed showed a weak effect on the welding power, but the need of power increased with the increase of the rotation speed. The measured power was found to be in agreement with the computed one through a theoretical work established by Heurtier et al. [2].
\end{abstract}

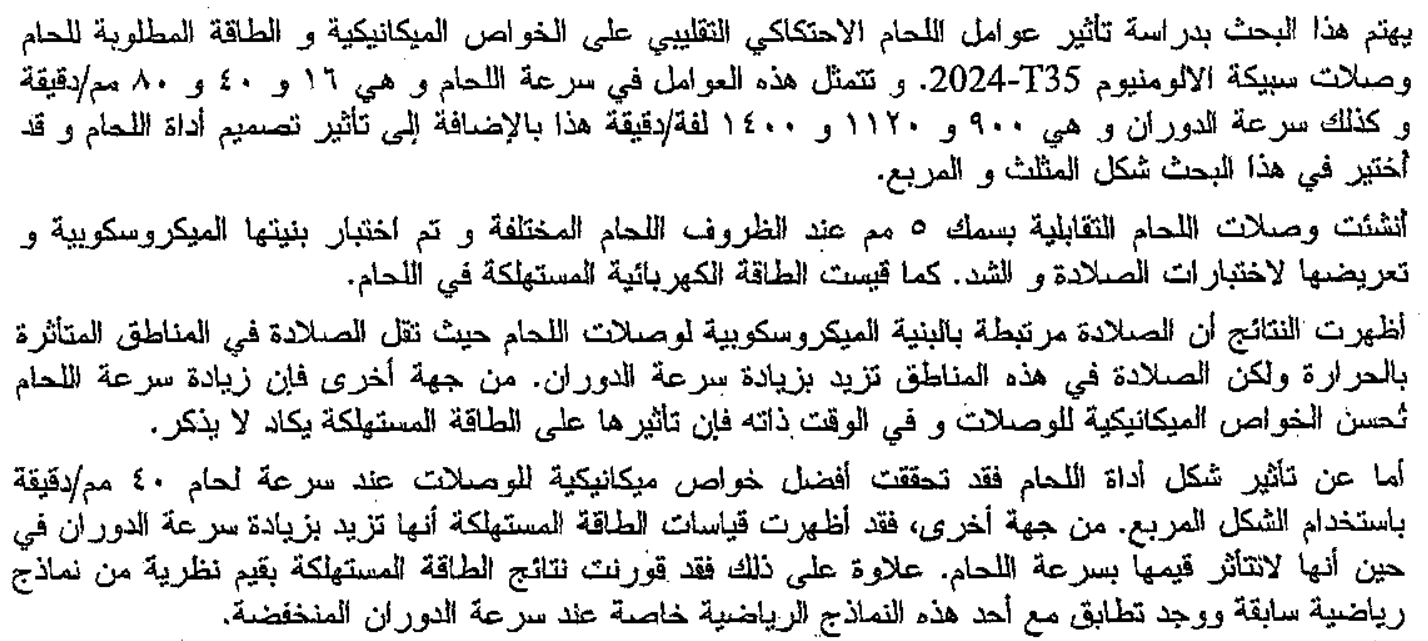

Keywords: Friction stir welding, Welding speed, Rotation speed, Welding power, AA22024-T35.

\section{INTRODUCTION}

The quality of friction stir processed (FSP) zone is controlled by the welding parameters (rotational speed, welding speed and axial force) and also by tool geometry (pin dimensions, pin profile, shoulder diameter etc.). Optimization of all these parameters is very essential to obtain defect free joints. Elangovan and Balasubramanian [3] had studied the effect of welding speed and tool pin profile on FSP zone formation in AA2219 aluminum alloy. They found that the formation of defect free FSP zone is also influenced by both welding speed and pin profile. The formation of defects and discontinuities are controlled by the above parameters and these defects and discontinuities obviously influence the tensile. properties of the FSW joints. Moreover, the joint fabricated using square pin profile at a certain welding speed of $0.76 \mathrm{~mm} / \mathrm{s}$ exhibited maximum tensile strength, higher hardness and finer grains in the FSP region compared to other joints.

The flow of the base material on the advancing side and the retreating side is different. The material on the retreating side never enters into the rotational zone, but the material on the advancing side form the fluidized bed near the pin and rotates around it [4].

When the welding tool moves forward along the welding line, there are many micro-pores left behind the tool, and each micro-pore was filled by the tool at the same time. So, the friction stir welding can be considered as micro-pores generation and disappearing procedure. Faster the welding speed is, larger is the pore. When welding and rotation speeds are constant, pores occur at small welding pressure [5]. 
In addition, Lee et al. [6] reported that the hardness of the weld nugget of FSW 6061Al at higher rotation rates was higher than that at lower rotation rates due to a higher density of spherical-shaped reprecipitates. However, when both rotation rate and welding speed change, it was hard to evaluate quantitatively the parameter dependence of the thermal input and mechanical properties [7]. For the precipitationhardened aluminum alloys FSW creates a softened region in the HAZ that has the lowest hardness within the entire weld, due to significant dissolution/coarsening of the precipitates during the FSW thermal cycle [8, 9]. Thus, the HAZ exhibits the lowest hardness and strength, and the fracture occurs usually in the $\mathrm{HAZ}[7,9]$. Therefore، the hardness profile of the FSW aluminum alloy joint is a direct indicator of microstructural evolution during FSW as concluded by Liu and $\mathrm{Ma}$ [10].

The development of mathematical models can greatly contribute to better understanding any industrial process' particularly FSW. A validated model has the potential to produce reliable information about the deformation and mixing patterns that are important when designing FSW tools and thus should be capable of producing welds free of defects and voids [11].

Although several numerical models of friction stir welding have been developed for the calculation of heat generation rate [12-14], heat transfer, and materials flow $[4,14-16]$, their testing has, for the most part, been limited to comparison of the numerically predicted temperature vs. time plots with the corresponding experimental data. A rigorous validation of numerical models must include examination of model capabilities to predict several important features of FSW such as the torque and power needed for welding and the geometry of the stir zone as a function of important welding variables over a wide range of values. But new researches evaluated by Arora et al. [17] and El-Domiaty and Abd El-Hafez [18] studied the power requirement for. FSW through modeling. They concluded that the welding speed has neglected effect on the welding power but the increase of the rotation speed increases the welding power because it becomes easier for the material to flow at higher temperatures and strain rates.

Other thermomechanical models were established by Zhang and Zhang [19-22] concluded that when the welding speed becomes higher, the rotating speed must be increased simultaneously to avoid any possible welding defects such as voids. 'The simultaneous increase of the rotating and the welding speeds can lead to the increase of the residual stress. The maximum temperature in the FSW process can be increased with the increase of the rotating speed. Also, the power needed for FSW is increased with the increase of the welding speed and the rotation speed.

In this study, the hardness distribution, tensile properties and fracture characteristics of AA2024T35 plates friction stir welded using triangular and square tool profiles at different rotation and welding speeds were investigated. Also, the consumed welding power was measured and evaluated with two models established elsewhere [1,2].

\section{EXPERIMENTAL WORK}

The base alloy, used in this study, is the hot rolled aluminum alloy 2024-T35, $5 \mathrm{~mm}$ thickness, $50 \mathrm{~mm}$ width and $200 \mathrm{~mm}$ length. The chemical composition of AA2024-T35 is listed in table I. Two plates were friction stir welded normal to the rolling direction at different welding speeds $(16,40$ and $80 \mathrm{~mm} / \mathrm{min})$ and at different rotation speeds $(900,1120$ and 1400 rpm). An equal welding force can be obtained by controlling the plunge depth of the welding tool, since the friction stir zone of all the specimens have the same thickness. Other friction stir welding process parameters are kept constant.

Table I The chemical composition of Al-alloy 2024T35

\begin{tabular}{|l|l|l|l|l|l|l|l|}
\hline \multicolumn{7}{|c|}{ Chemical composition, wt.\% } \\
\hline $\mathrm{Si}$ & $\mathrm{Fe}$ & $\mathrm{Cu}$ & $\mathrm{Mn}$ & $\mathrm{Mg}$ & $\mathrm{Cr}$ & $\mathrm{Zn}$ & $\mathrm{Al}$ \\
\hline 0.50 & 0.37 & 4.4 & 0.6 & 1.5 & 0.12 & 0.25 & $\mathrm{Bal}$ \\
\hline
\end{tabular}

According to the previous studies $[2,22,23]$, triangular and square tool profiles were chosen to carry out the FS-joints in this study.

Non-consumable tools made of X40 CrMoV 51 have been used to fabricate the joints. The tools were treated by hardening and tempering processes, where the hardness was increased to 54 HRC: The tools have a concave shoulder of $20 \mathrm{~mm}$ diameter with slope of $10^{\circ}$ and the triangle and square pin profiles of $5 \mathrm{~mm}$ root diameter and $4.8 \mathrm{~mm}$ length were used.

The initial joint configuration is obtained by securing the plates in position using mechanical clamps. Single pass welding procedure has been used to fabricate the joints.

The electrical power, during welding processes, was measured using clamp-meter. The power $(q)$ was calculated using the following equation for 3-phase;

$q=\sqrt{3} V I \cos \theta \quad$ (watt)

Where $V$ is the voltage, $I$ the current in ampere and $\cos \theta$ is the power factor. The voltage ( $V$ ) was constant around 380 volts and the power factor is 0.8 . Therefore, the power calculations depend only on the current value.

After welding, the FSW samples were crosssectioned perpendicular to the welding direction for 


\section{H. Abd El-Hafez "Mechanical Properties and Welding power of Friction Stirred AA2024-T35 Joints"}

microstructural examinations by optical microscopy, hardness measurement, and tensile test. Three tensile specimens are tested at each condition and their average represents one point data.

Vickers microhardness distribution was measured from the weld center on both retreating and advancing sides. Vickers microbardness testing machine has been employed for measuring the hardness across the joint with $0.5 \mathrm{~kg}$ load.

\section{RESULTS AND DISCUSSION}

\subsection{Microstructural Characteristics}

Macrostructure shows that, at $40 \mathrm{~mm} / \mathrm{min}$, the weld is perfect and no obvious defects produced. The materials were stirred, combined sufficiently and the weld was completely filled. On the other hand, voids were noticed near the weld root when the welding speed is $80 \mathrm{~mm} / \mathrm{min}$. Also, the defects were increased at the higher rotation speed of $1400 \mathrm{rpm}$.

The voids produced near the welding line are normal; in fact, additional superplasticity was needed to fill the gap of the base metal [5].

Figure 1 presents micrographs showing the evaluation of 2024-T35 microstructure, carried out at $40 \mathrm{~mm} / \mathrm{min}$ for square profile, in FS-region. Figure 1-a shows the microstructure under the tool shoulder whereas the bottom of specimen is shown in Fig. 1-b. it can be seen, in Fig. 1, the difference of the white areas. This difference may be attributed to the higher heat generated near the tool shoulder where coarser grains can be noticed in the thermal mechanical affected zone (TMAZ). Also, the $\mathrm{CuAl}_{2}$ phase (dark area) is distributed in both nugget and TMAZ [25].

In fact, the welding parameters have not a clear effect on the microstructure observations using the optical microscope. However, the Sutton et al. [25] proved that band spacing will decrease as the welding speed is reduced. Smaller band spacing should result in a more homogeneous structure within the weld. Demonstrate that the particles contain higher concentrations of $\mathrm{Cu}, \mathrm{Fe}, \mathrm{Mg}$ and $\mathrm{Mn}$ than the surrounding material [25].

From the macrostructure analysis, it can be inferred that the formation of defect free FSP zone is a function of tool profile and the welding speeds used:

\subsection{Hardness Distributions}

Hardness distribution on the transverse cross-section of the joints at different welding speeds and rotation speed of $1120 \mathrm{rpm}$ for square profile is shown in Fig.2.

Minimum hardness appeared in the heat affected zone (HAZ) and its value increased with the increase of the welding speed. The softened zones existing on both sides of the HAZ were shifted toward the welding centre line as the welding speed increased [26]. The lower hardness values of the HAZ can be attributed mainly to the coarsening of precipitates where not present. Also, the softened area is narrower for the higher welding speed than that for the lower welding speed [24]. The welding speed of $40 \mathrm{~mm} / \mathrm{min}$ has the same trend in advanced side but on retreating side the hardness is higher than the other speeds in the soft zone.

Results from metallurgical and hardness measurements show that the friction stir welding process can create a segregated banded microstructure consisting of alternating hard particle rich (dark areas) and hard particle-poor (white areas) regions.

\subsection{Fracture Behaviour}

The fracture behaviour for the tensile specimens was studied and it has two trends, the first one where the fracture happen at the end of tool shoulder usually at the retreating side. The second fracture path is at the weld line (nugget).

Most joints fractured at the retreating side are due to variation in temperature distribution and flow of the material in the weld zone with corresponding hardness distribution and strained region. Moreover, due to different deformation of various zones, the strain becomes localized, which induces constraint and fracture occurs, where the strain localization is maximum. For this alloy the retreating side of the weld zone has been found to be the major fracture site where strain localization occurred $[3,27]$.

\subsection{Tensile Results}

Figure 3 illustrates the effect of welding speed on the yield stress, the tensile strength, and the elongation percent for the fabricated triangular profile joints. The effect of welding speed was investigated at a constant rotation speed of $1120 \mathrm{rpm}$. The results show a noticeable improvement of the mechanical properties from $40 \mathrm{~mm} / \mathrm{min}$ up to $80 \mathrm{~mm} / \mathrm{min}$ but the increase of welding speed from 16 to $40 \mathrm{~mm} / \mathrm{min}$ does not change the tensile properties. This improvement, at $80 \mathrm{~mm} / \mathrm{min}$, may be attributed to the more homogeneity of the weld nugget and less pores producing a sound joint.

Also, the results of square profile with the above parameters are illustrated in Fig. 4 . One can see that the increase of the welding speed from 16 to 40 $\mathrm{mm} / \mathrm{min}$, the yield strength as well as the tensile strength increases and remain almost undergo above this speed.

The tensile properties and fracture locations depend mainly on the welding defects and hardness of the joint. When joints were free from defects, their tensile properties were controlled by hardness and fracture occurred in the HAZ on the side that show minimum hardness [26]. These results show better 
properties at $40 \mathrm{~mm} / \mathrm{min}$ and this may be due to the sufficient heat generation to fill, in time, the pores.

Lower welding speed resulted in higher temperature and slower cooling rate in the weld zone which causes grain growth and severe clustering of $\mathrm{CuAl} \mathrm{Al}_{2}$ precipitates $[3,28]$.

The effect of the tool profile was illustrated in Fig. 5. Insignificant effect of the tool profile at lower welding speed was noticed. At higher welding speed of $40 \mathrm{~mm} / \mathrm{min}$, the square profile achieves higher strength compared to the triangular one. Otherwise, an improvement for the triangular profile was noticed with increasing the welding speed to $80 \mathrm{~mm} / \mathrm{min}$ but neglected change to that of square profile. Also, at 80 . $\mathrm{mm} / \mathrm{min}$, the tool profile has a weak effect on the strength. However; it is clear that the welding speed of $40 \mathrm{~mm} / \mathrm{min}$ can be considered as a critical speed for both profiles. The square profile has sufficient heat generation whereas the triangular one achieves this heat at higher speed of $80 \mathrm{~mm} / \mathrm{min}$. The achieved higher strength using the square profile at 40 $\mathrm{mm} / \mathrm{min}$ may be due to the higher pluses/s produced than by the triangular one. The higher number of pulsating action produces finer grained microstructure with uniformly distributed precipitates $(\mathrm{CuAl})_{2}$ and in turn yields higher strength and hardness as explained by previous researchers [3, 24]. Moreover, the behaviour of the strength at 80 $\mathrm{mm} / \mathrm{min}$ for different tool profiles may be attributed to the stirring effect of the welding tool whose becomes weaker, which is the reason for the occurrence of weld flow as mentioned by Zhang and Zhang [22].

Otherwise, as the square profile achieves best properties, the effect of the rotation speed on the mechanical properties of the FS-joints was carried out, using square profile, at constant welding speed of $40 \mathrm{~mm} / \mathrm{min}$. Fig. 6 shows that the strength as well as the elongation percent has slight improvement at $1120 \mathrm{rpm}$, while the yield strength has neglected changes. The improvement of the mechanical properties at $1120 \mathrm{rpm}$ may be associated with good stirring action with uniformly distributed precipitates $\left.(\mathrm{CuAl})_{2}\right)$. On the other hand, the strength has lowest value at higher rotation speed of $1400 \mathrm{rpm}$ which can be attributed to the increase of pores in the nugget zone $[5,19-22]$.

\subsection{Welding Power}

Figure 7 illustrates the measured welding power affected by different welding parameters. The variation of the welding speed does not significantly. affect the power needed for FSW where the plastic deformation, due to the temperature rise, is increased with the increase of the welding speed [22, 29]. Otherwise, the square tool profile needs more power than the triangular one at lower welding speed may be as a result of the excess of pluses number per unit time than the triangular profile. However, by increasing the welding speed to $40 \mathrm{~mm} / \mathrm{min}$, the power difference occurred by tool profile can be neglected which is eliminated at higher welding speed of $80 \mathrm{~mm} / \mathrm{min}$.

The effect of the tool profile on the needed power decreases with the increase of the welding speed because when the welding speed is high, the stirring effect of the welding tool profile becomes weaker, which is the reason for the occurrence of weld flow [22].

The energy was computed, also, by dividing the power by the welding speed, Fig. 8 . The energy per unit length decreases with the increase of the welding speed since the energy is inversely proportional to the welding speed [17].

On the other hand, the effect of the rotation speed on the welding power for the square profile is illustrated in Fig. 9. The welding power needed for FSW is increased significantly with the increase of the rotation speed. Increasing the rotation speed increases the power input to the weld, while the welding speed had little impact $[21,30]$.

Many researchers established different models to compute the welding power needed for FSW. Two models, established in previous studies, are used to evaluate the experimental results of the consumed power (q) as follows;

$$
\begin{array}{lll}
q=\frac{4 \pi^{2}}{3} \mu P \omega R^{3} & \text { (Watt) } & \text { Frigaad et al. [1] } \\
q=\frac{2 \pi}{3} \mu P \omega R_{S}^{3} & \text { (Watt) } & \text { Heurtier et al. [2] }
\end{array}
$$

Where $\mu$ is the friction coefficient, $P$ pressure $(\mathrm{Pa}), \omega$ the tool angular speed ( $\mathrm{rad} / \mathrm{s}), R_{S}$ tool shoulder radius and $R$ is the pin radius. In fact, there is no experimental work for the determination of the friction coefficient on the tool-plate interface till now. Zhang and Zhang [20] reported that the predicted temperature is very similar to the experimental measurement when the friction coefficient is taken as 0.3 . So, this value is also adopted in the current work. The pressure $P$ equals force divided by the shoulder area and the measured force by Elangovan and Balasubramanian [3] was 12 $\mathrm{KN}$ for AA2219 which is used in this study.

Figure 10 shows the-experimental and computed results at different rotation speeds. It is clear that the power increased with the increase of the rotation speed. Furthermore, the measured power is, nearly, matched with the second theoretical model established by Heurtier et al. [2]. The matching is excellent at the lower rotation speed of $900 \mathrm{rpm}$ but the slope of the model is greater than that of the measured power. The difference increases by the 
increase of the rotation speed could be attributed to the heat generated increases or to the sliding between tool and the metal or other parameters are not considered by Heurtier et al. [2].

\section{CONCLUSION}

A series of controlled friction stir welds have been manufactured using $5 \mathrm{~mm}$ thick, 2024-T35 aluminum rolled sheet material. Metallurgical investigation, hardness test, and tensile test results, as well as the measured welding power values show that;

1- The welding speed has a noticeable effect on the hardness distribution. As the welding speed increases, the bardness of the softened TMAZ increases, and the softened TMAZ is shifted toward the weld line. Moreover, the hardness distribution affects the fracture path which occurs usually in the softened zone.

2. The tensile strength has a bigher value of 80 $\mathrm{mm} / \mathrm{min}$ welding speed for triangular profile, but the same strength value is achieved at $40 \mathrm{~mm} / \mathrm{min}$ for square tool profile. The combined effect of higher number of pulsating stirring action during metal flow and an optimum welding speed may be the reason for higher tensile properties of the joint fabricated at a welding speed of $40 \mathrm{~mm} / \mathrm{min}$ using square tool profile. At higher speed of $80 \mathrm{~mm} / \mathrm{min}$ the tool profile has insignificant effect due to a weaker stirring effect of the welding tool.

3- Increasing the rotation speed increases the welding power, while the welding speed has a little effect.

4- The measured power agrees with corresponding values calculated using a model established by Heurtier et al. [2], especially at lower rotation speed. The computed power as well as the measured one has a linear relation with the rotation speed. The computed power shows a higher slope than the measured power. Such deviation could be due to the increase of slipping between the tool and the metal at higher rotation speed, or due to a possible lack of modelassumptions accuracy.

\section{REFERENCES}

[1] Frigaad, O., Grong, O., Midling, O.T., 2001, A process model for friction stir welding of age hardening aluminum alloys, Metallurgical and Materials Transactions A, 32A, 1189-1200.

[2] Heurtier, O. P., Jones, M.J., Desrayaud, C., Driver, J.H., Montheillet, F., Allehaux, D., 2006, Mechanical and thermal modelling of Friction Stir Welding Journal of Materials Processing Technology 171, 348-357

[3] Elangovan, K., Balasubramanian, V., 2007, Influences of tool pin profile and welding speed on the formation of friction stir processing zone in
AA2219 aluminium alloy, Materials Science and Engineering A 459, 1-2, 7-18

[4] Zhang, H.W, Zhang, Z, Chen, J.T, 2005, The finite element simulation of the friction stir welding process, Metallurgical and Materials Transactions A, Vol. 403, 305-316.

[5] Zhang, H., Lin, S.B., Wu, L., Feng, J.C., Ma, Sh. L., 2006, Defects formation procedure and mathematic model for defect free friction stir welding of magnesium alloy, Materials and Design 27, 805-809.

[6] Lee, W.B., Yeon, Y.M., Jung, S.B., 2004, Mechanical properties related to microstructural variation of $6061 \mathrm{Al}$ alloy joints by friction stir welding, Materials transactions 45, 1700-1705.

[7] Ren, S.R., Ma, Z.Y., Chen, L.Q., 2007, Effect of welding parameters on tensile properties and fracture behavior of friction stir welded $\mathrm{Al}-\mathrm{Mg}-\mathrm{Si}$ alloy Scripta Materialia 56, 69-72.

[8] Lim, S., Kim, S., Lee, C.G., Kim, S., 2004, Tensile behavior of friction-stri-welded Al 6061-T651, Metallurgical and Materials Transactions A, 35A, 2829-2835.

[9] Mishra, R.S., Ma, Z.Y., 2005, Friction stír welding and processing, Materials Science and Engineering R 50, 1-78.

[10] Liu, F.C., Ma, Z.Y., 2008, Influence of tool dimension and welding parameters on microstructure and mechanical properties of friction-stir-welded 6061-T651 aluminum alloy, Metallurgical and materials TransactionsA, 39A.

[11] Vilac, a, P., Quintino, L., dos Santos, J.F., 2005, Analytical thermal model for friction stir welding, Joumal of Materials Processing Technology 169, $452-465$.

[12] Khandkar, M.Z.H., Khan, J.A., Reynolds, A.P., 2003, Science and Technology of Welding and Joining 8 (3), 165-174.

[13] Schmidt, H, Hattel, J, Wert, J, 2004, An analytical model for the heat generation in friction stir weldingModelling Simul. Mater. Sci. Eng. 12, 143-157.

[14] Nandan, R., Lienert, T.J., DebRoy, T., 2008, Toward reliable calculations of heat and plastic flow during friction stir welding of Ti-6Al-4V alloy, International Journal of Materials Research 99 (4), 434-444.

[15] Nandan, R., Roy, G.G., Lienert, T.J., DebRoy, T., 2006, Numerical modelling of 3D plastic flow and heat transfer during friction stir welding of stainless steel, Science and Technology of Welding and Joining $11(5), 526-537$.

[16] Nandan, R., Roy, G.G.,. Lienert, T.J., DebRoy, T., 2007, Three-dimensional heat and material flow during friction stir welding of mild steel, Acta Materialia 55, 3, 883-895.

[17] Arora, A., Nandan, R., Reynolds A.P., DebRoy, T., 2009, Torque, power requirement and stir zone geometry in friction stir welding through modeling and experiments, Scripta Materialia 60, 13-16 
[18] El-Domiaty, A., Abd El-Hafez, H., 2007, An energy model for friction stir welding, Conf. Materials Science and Technology, DetroitMichigan, USA.

[19] Zhang, Z., Zhang, H.W., 2007. Numerical studies on the effect of axial pressure in friction stir welding. Sci. Technol. Weld. Joining 12, 226-248.

[20] Zhang, Z., Zhang, H.W., 2008. A fully coupled thermo-mechanical model of friction stir welding. Int. J. Adv. Manuf. Technol. 37, 279-293.

[21] Zhang, Z., Zhang, H.W., 2009. Numerical studies on controlling of process parameters in friction stir welding, journai of materials processing technology 209, 241--270.

[22] Zhang, Z., Zhang, H.W., 2009, Numerical studies on the effect of transverse speed in friction stir welding, Materials and Design 30, 900-907.

[23] Abd El-Nasser, G., El-Bagdady, A., Abd El-Hafez, H., 2007, Effect of the friction stir welding parameters on the mechanical properties of Al 5083 joint, Al-Azahar Engineering 9th. Int. Conf., Cairo, Egypt

[24] Elangovan, K., Balasubramanian, V., Babu, S., 2009, Predicting tensile strength of friction stir welded AA6061 aluminium alloy joints by a mathematical model, Materials and Design 30 , $188-193$.
[25] Sutton, M.A., Yang, B., Reynolds, A.P., Taylor, R., 2002, Microstructural studies of friction stir welds in 2024-T3 aluminum, Materials Science and Engineering A323, 160-166.

[26] Khodir, S.A., Shibayanagi, T., 2008, Friction stir welding of dissimilar AA2024 and AA7075 aluminum alloys, Materials Science and Engineering B 148, 1-3, 82-87.

[27] Babu, C. S., El-Gizawy, Sherif, A., 2008, Characterization of friction stir welding process behaviour using numerical and physical modeling techniques, Proc. of the $9^{\text {th }}$. Int. Conf. on Mech. Design and Prod. (MDP-9), Cairo, Egypt.

[28] Lee, W.B. Yeon, Y.M, Jung, S.B, 2003, Evaluation of the microstructure and mechanical properties of friction stir welded 6005 aluminum alloy, Material Science and Technology, 19, 1513-1518.

[29] Atharifar, H, D Lin, D, Kovacevic, R, 2008, Numerical and experimental investigations on the loads carried by the tool during friction stir welding, ASM International, Journal of Materials Engineering and Performance, . DOI: 10.1007/s1 1665-008-9298-I.

[30] Colegrove, P.A., Shercliff, H.R., 2005, 3Dimensional CFD modelling of flow round a threaded friction stir welding tool profile, Journal of Materials Processing Technology 169, 320-327.

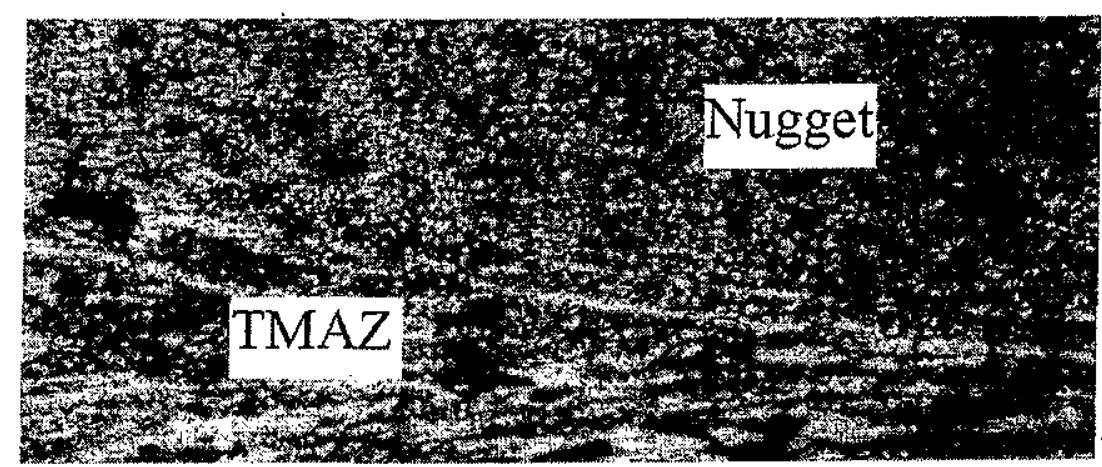

(a) Under shoulder.



(b) Bottom.

Fig. 1 Micrographs of the microstructure of AA2024-T35 [X100] 
H. Abd El-Hafez "Mechanical Properties and Welding power of Friction Stirred AA2024-T35 Joints"



Fig. 2 Hardness distribution, at different welding speeds, for square profile joints.

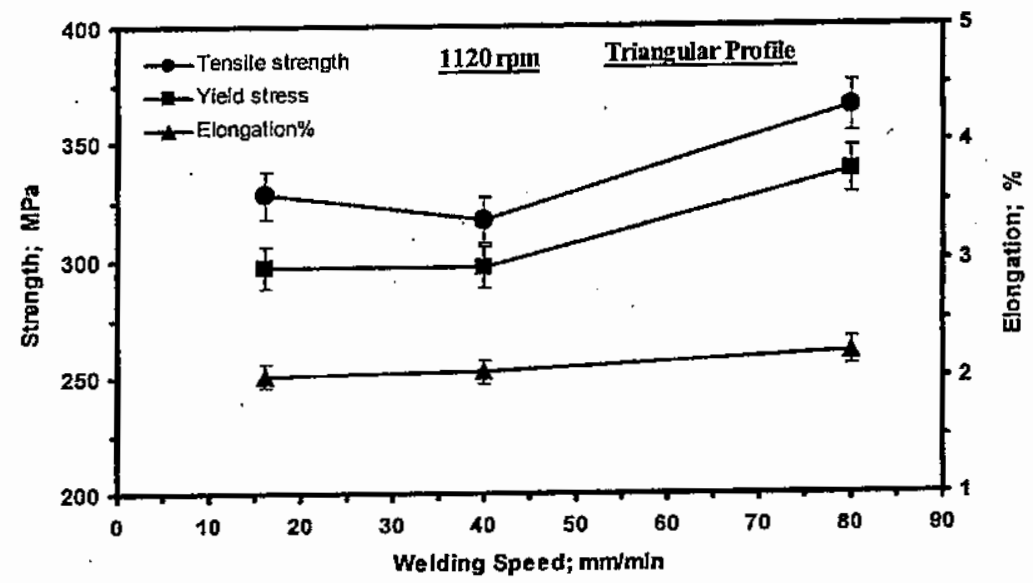

Fig. 3 Effect of welding speed on the mechanical properties of the FS-joints using triangular profile.

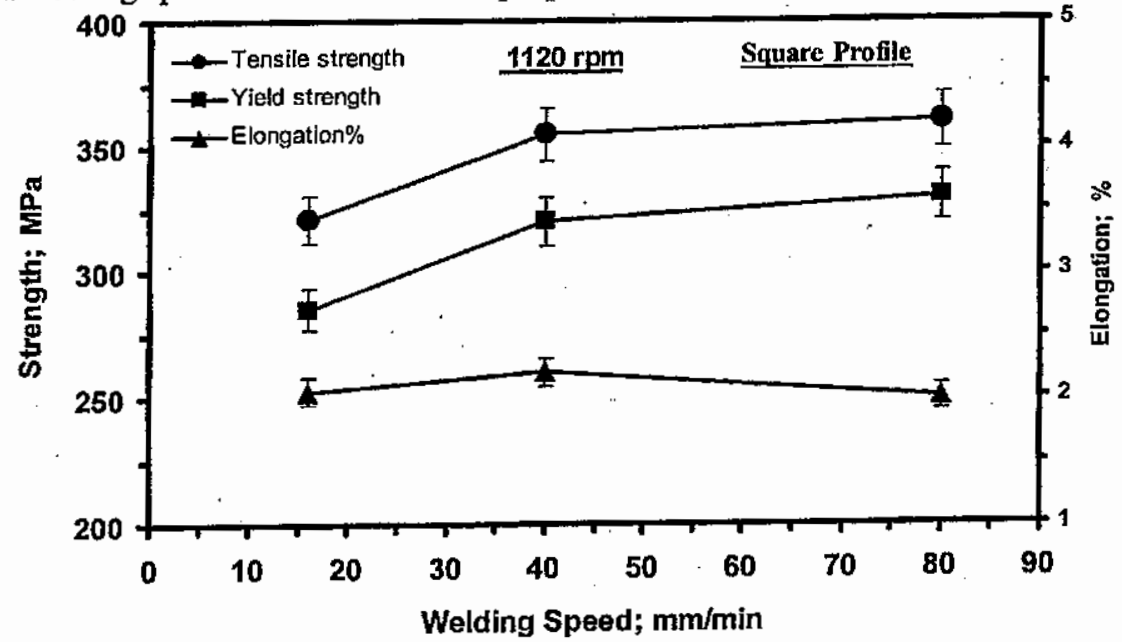

Fig. 4 Effect of welding speed on the mechanical properties of the FS-joints using square profile. 


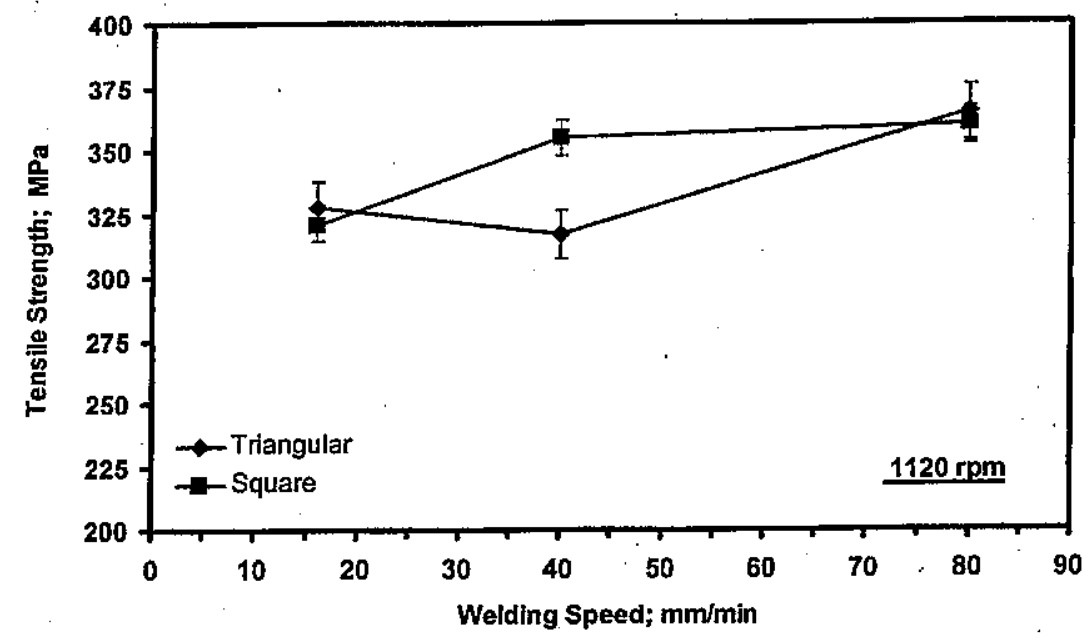

Fig. 5 Tool profile and the welding speed effects on the FS-joints strength.

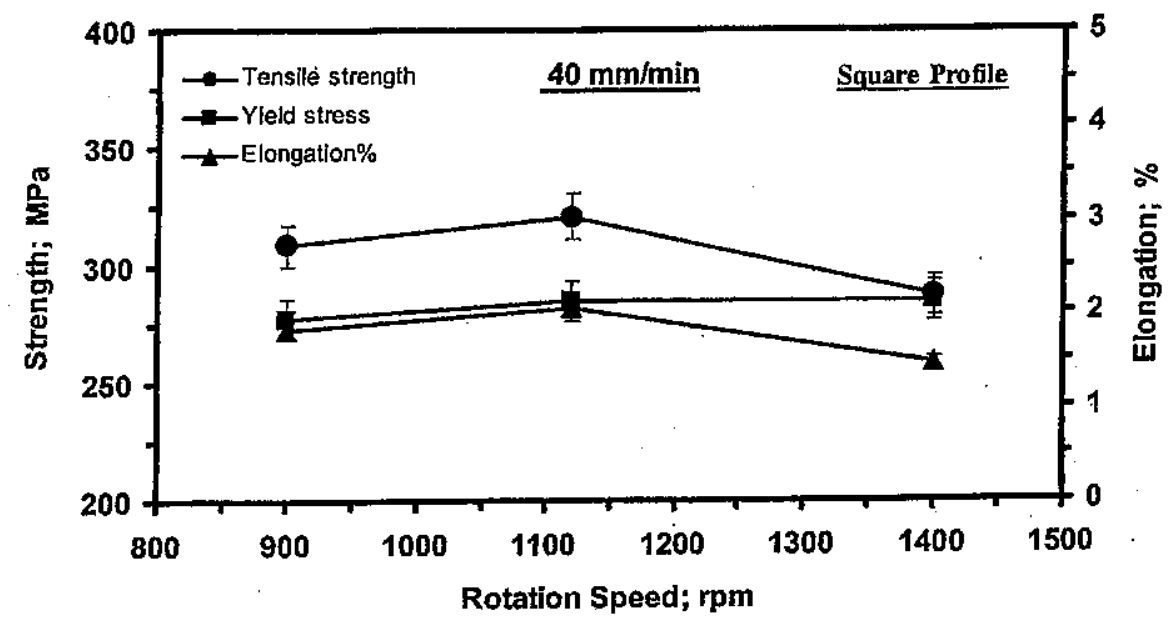

Fig. 6 Mechanical properties of AA2424-T35 FS-joints at different rotation speeds

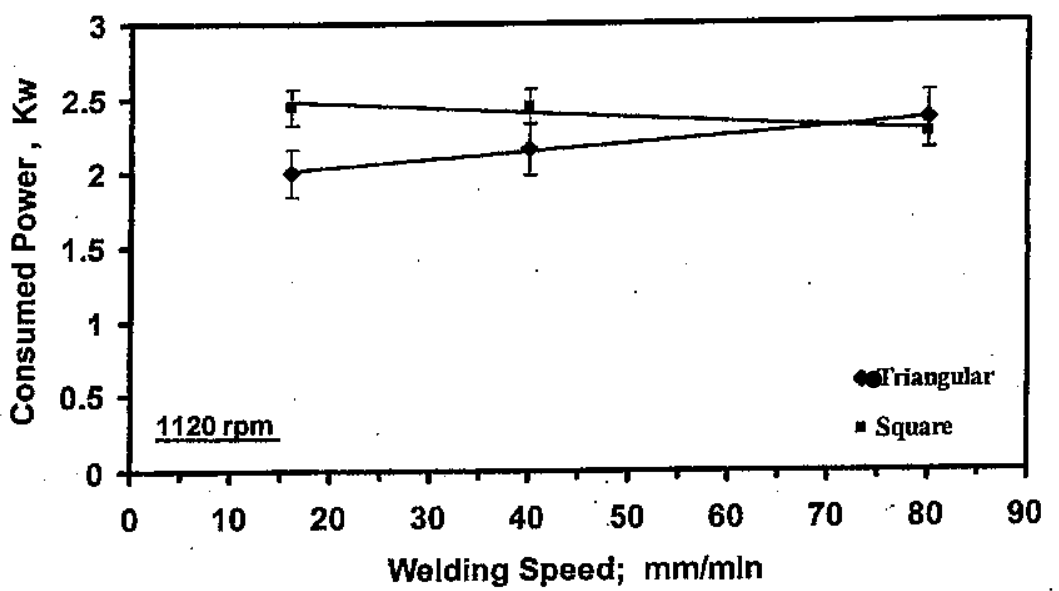

Fig. 7 Effect of welding speed and tool profile on the welding power 


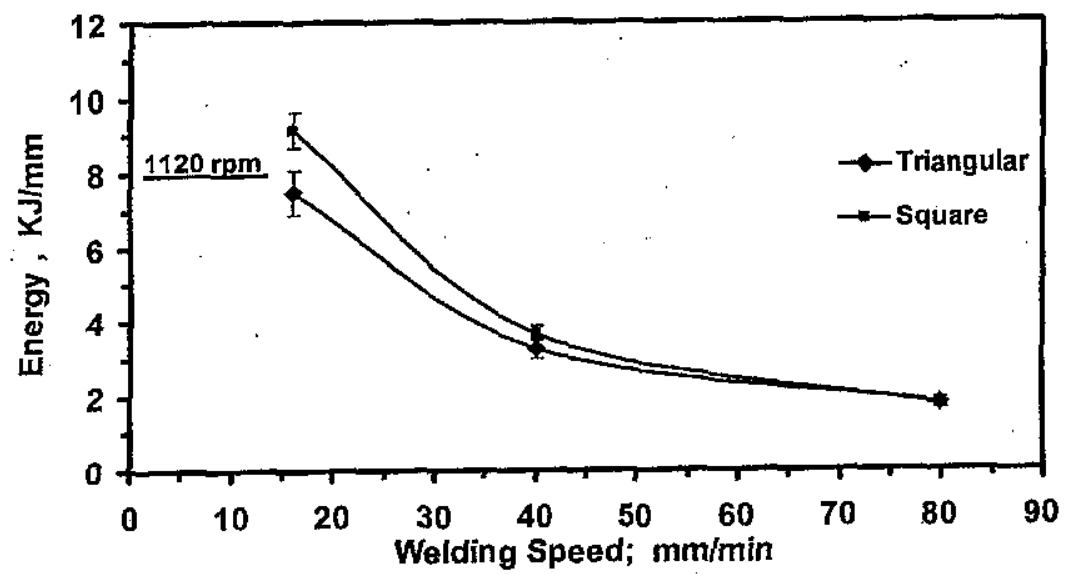

Fig. 8 Effect of welding speed and tool profile on the energy

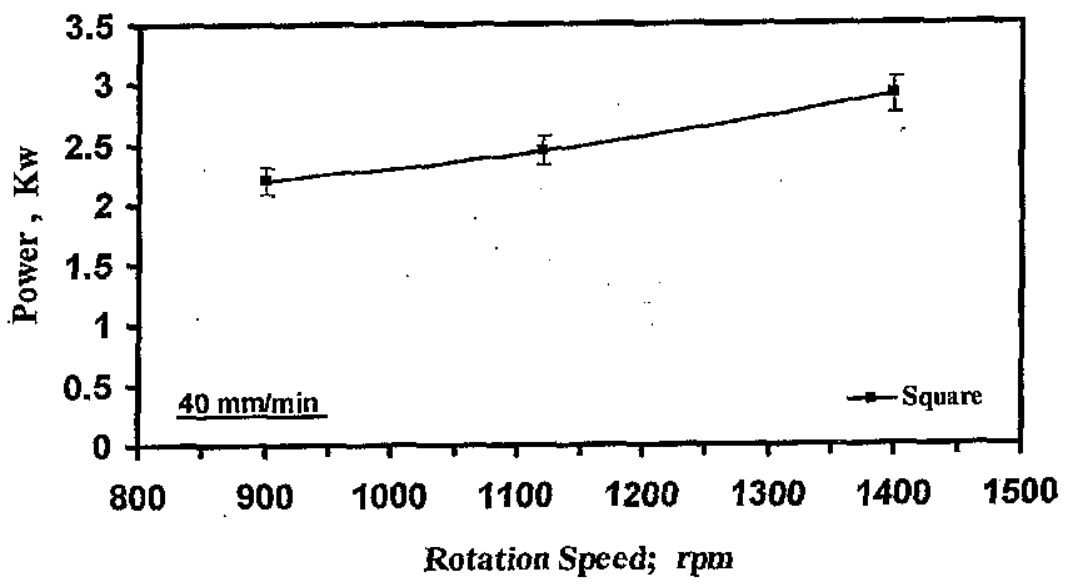

Fig. 9 Welding power and rotation speed for square tool profile



Fig. 10 Evaluation the experimental welding power by two models at different rotation speed. 